\title{
AUTONOMOUSLY RIDING GOOGLE MAPS TO TRAVEL TO ENGLISH SPEAKING COUNTRIES: LINGUISTIC LANDSCAPE
}

\author{
Siusana Kweldju \\ Universitas Negeri Malang \\ siusana.kweldju.fs@um.ac.id
}

\begin{abstract}
All English Department students dream to visit Englishspeaking countries. One reason is that they want to practice their English to communicate with native speakers in real communication, and to immerse themselves into the English language-rich environment. However, only a small portion of students have the means and opportunity to do so. This paper will show how Google Maps can help students to virtually travel to English speaking countries and improve their English linguistically, pragmatically and interculturally. Actually, languages, including English, are available in public spaces and make up the linguistic landscape of a territory or a region, and linguistic landscape is potential for the teaching and learning of second and foreign languages. The linguistic element of signs is made creatively with clear, interesting, fresh and ready to understand English. They are valuable for learners to improve their English.
\end{abstract}

Keywords: Linguistic Landscape, Pragmatic Implication, Culture, Google Maps

\section{LINGUISTIC LANDSCAPE}

Linguistic landscape is languages displayed all around us in public spaces such as on public and commercial signs in a given territory or region; for examples, textual forms on shop windows, shop names, posters, official notices, traffic signs, announcements, regulatory parking signs, safety signs, directory signs, and double-sided pavement signs (Landry \& Bourhis, 1997). Public signs are accessible to everyone and free; we can find them at the bus stop, in the park, at school, on campus, in a shopping mall, in a bank, in a zoo and in traditional markets.

Today the number of public and commercial signs has increased enormously, especially in urban, commercial areas of cities. Advertising boards, signs and trade displays are now dominant part of street scene in all shopping areas. Linguistic landscape has been used as a language learning resource, especially for developing learners' linguistic, pragmatic, and intercultural competence. According to Hewitt-Bradshaw (2014) linguistic landscape is potential for propelling learners' language and literacy development, as it provides a good source for language learning and teaching, and is very useful to increase the learners' critical language awareness.

\section{FOREIGN LANGUAGE LEARNERS AND THE WISH TO VISIT THE TARGET COUNTRY}

Every English language learner wishes to visit and practice their English in the country where the language is used in daily and official situations. They can hear and see the language that they have learned in their textbooks. They want to meet more native speakers, and encounter a lot of useful words and expressions that they can encounter in situ. They will be surrounded with signage, notices, and announcement which are all written in English. As English speaking countries also belong to the most advanced countries in the world, a visit will also give them enriching experience and broaden their horizon about the urban culture in the technologically advanced country. In its own cultural landscape where everyone is the native speaker of English, English is used creatively in real-events in public spaces; being in that environment is vitally important for students to cultivate their curiosity and creative awareness about the use of English in producing the desired effects.

\section{LINGUISTIC-LANDSCAPE-BASED ACTIVITIES WITH GOOGLE MAPS}

Today with Google Maps students can virtually visit most places they want to visit: shopping areas, restaurants, hospitals, campuses, zoos, and theme parks, to mention some. In spite of all the opportunities, however, linguistic-landscape-based activities are only concentrated on major streets of cities with high density of signs. Using satellite imagery, Google Maps users can easily explore the 360- 
degree panoramic views of streets, just like their real life images. Moving forward, backward and turning around, learners can discover many different kinds of signs and fully immerse themselves in street view.

Students can virtually walk down any streets and turn around just by scrolling their mouse wheel. When they find interesting signs, they can easily tap and pinch to zoom in and out with a cell phone to clearly read the signs, or easily slide the mouse when they use their computers.

\section{Improving Linguistic Competence}

The linguistic element of street signs helps students to incrementally develop their linguistic skills, especially lexico-grammatical units. In the first language context, learners can incidentally and contextually learn the form, the meaning and the use of those signs-including the verbal texts-in their actual daily practices and customs. They may easily and repeatedly encounter all kinds of signs-such as the information, regulatory and warning signs-at the roadside and footway throughout their lives, and competently use them in their native language.

However, when they want to know how those signs are expressed in English, they need to deliberately learn them because they hardly encounter those signs in their daily life. The exposure to those target-language signs should also be deliberately facilitated. Not all target-language signs have their equivalents in their native language, and vice versa, because signs are culturally bound.

\section{Lexico-grammatical Units}

Lexicogrammatical units-known also as formulaic language units, lexical phrases or chunksare multiword strings or fragments which are similar to lexicon in being treated as a unit, but at the same time many of them are derived from the regular rules of syntax (Natinger \& De Carrico, 1992). Learning lexico-grammatical units is vitally important if learners want to approximate themselves to native speakers' competence, because native speakers have their own preferences for certain sequences of words that might appear as ready-made chunks (Wray, 2000).

As a form of unanalyzed whole, a chunk is readily produced by the speaker, and readily understood by the listener (Duraiswamy, 2014). In fact, vocabulary and grammar are interdependent and inseparable, and merge in lexico-grammatical units. According to Lewis (1997) language consists of grammaticalized lexis. Thus, the teaching of grammar is inseparable from the teaching of lexicon and vice versa. When the teaching of grammar and vocabulary are separated, second language learners will produce bizarre utterances. They may understand every single word in a sentence, but they cannot correctly get the right meaning of the sentence, and comprehension also becomes slow (Kweldju, 2001).

Most street signs are culture bound and they display an unlimited number of lexico-grammatical units. Signs such as "Changed traffic conditions", "End road work," and "Harbour Br: Detour" found in Sydney do not have the equivalents in Indonesia. "Changed traffic conditions" is a temporary traffic control sign to convey that a short-term construction work is underway. Barriers are erected to ensure the safety of the public and the workers working behind the barriers. Motorists are supposed to reduce their speed. "End road" sign conveys that motorists are leaving the area of the road under construction and they can accelerate back to the posted speed limit. The sign "Bicycle Signal" used in Canada, for example, is used to facilitate bicyclists to cross intersections in a safer way.
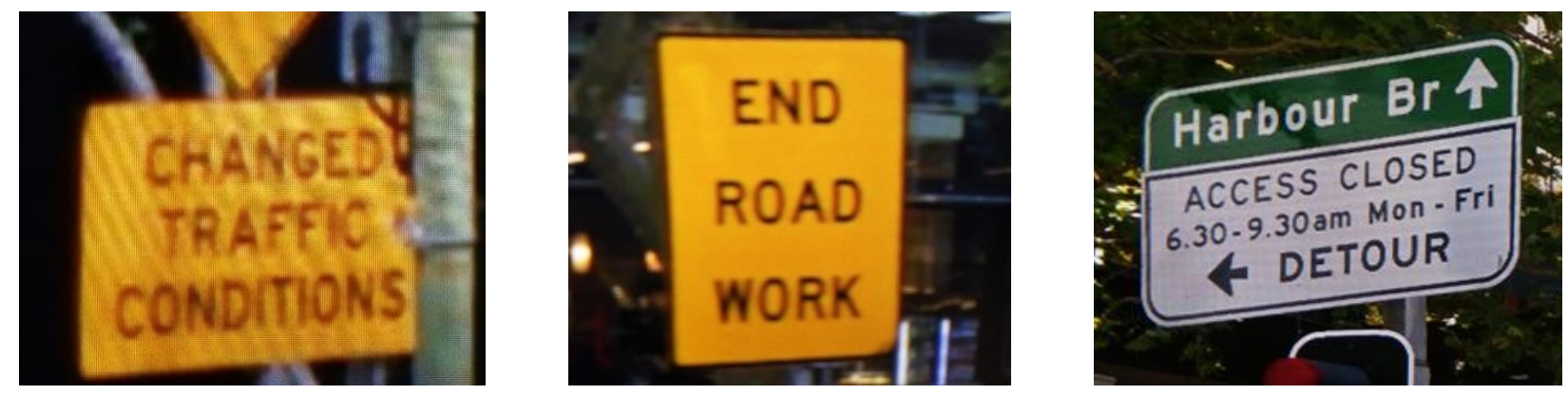

Learners are encouraged to discover the meanings of those signs, and explain them to the class. This activity will help them to develop their inquiry skill, lexicogrammatical skill and their fluency in English. There are innumerable signs for students to discover for practice. Some signs are globally common and learners can also find the equivalents in their first language in their own respective countries, and some are typically English and use longer phrases. The following a-single and a-fewwords warning signs are found almost everywhere in English-speaking countries: "Curb lane closed ahead", "Caution: Forklifts operate when amber lights flash", "Skateboard, bicycle riding prohibited on sidewalk," " Keep out: construction area," "Sidewalk closed: use other side," "No stopping any time," "Notice: double party prohibited at all-times," "Red light camera ahead," "Mondays and Wednesdays: Parking from $\$ 5.00 . "$ 

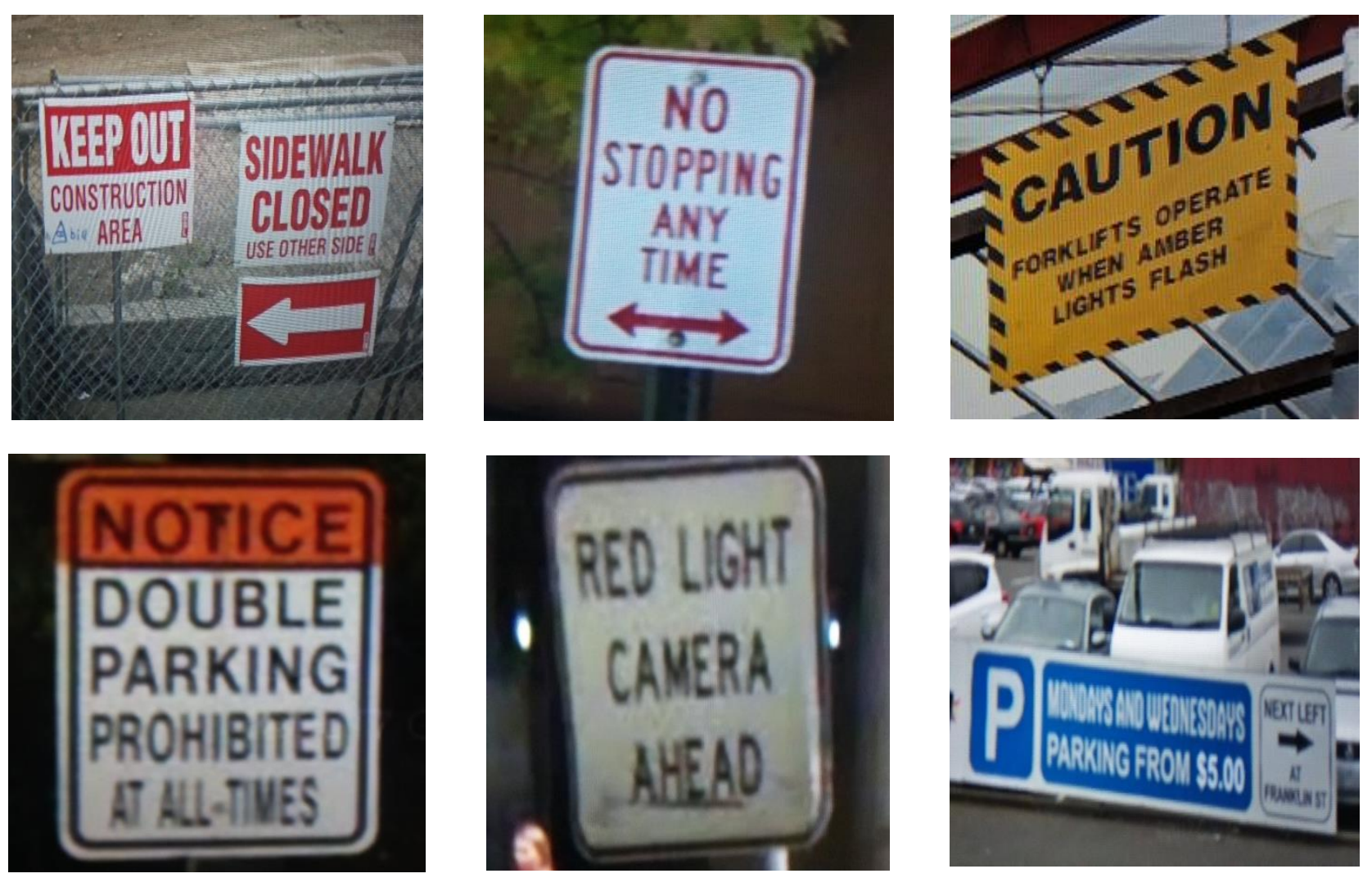

Students can also notice that most warning signs are not written grammatically, because of the limited size of the sign plates. The wording of the signs is kept to the minimum, and it should be clear, simple, short and easy to grasp the meaning. Then, all those forms become fixed lexico-grammatical units or fixed lexical phrases that learners have to learn. It will also be a good exercise for learners to understand them, and to restate them in full grammatical sentences.
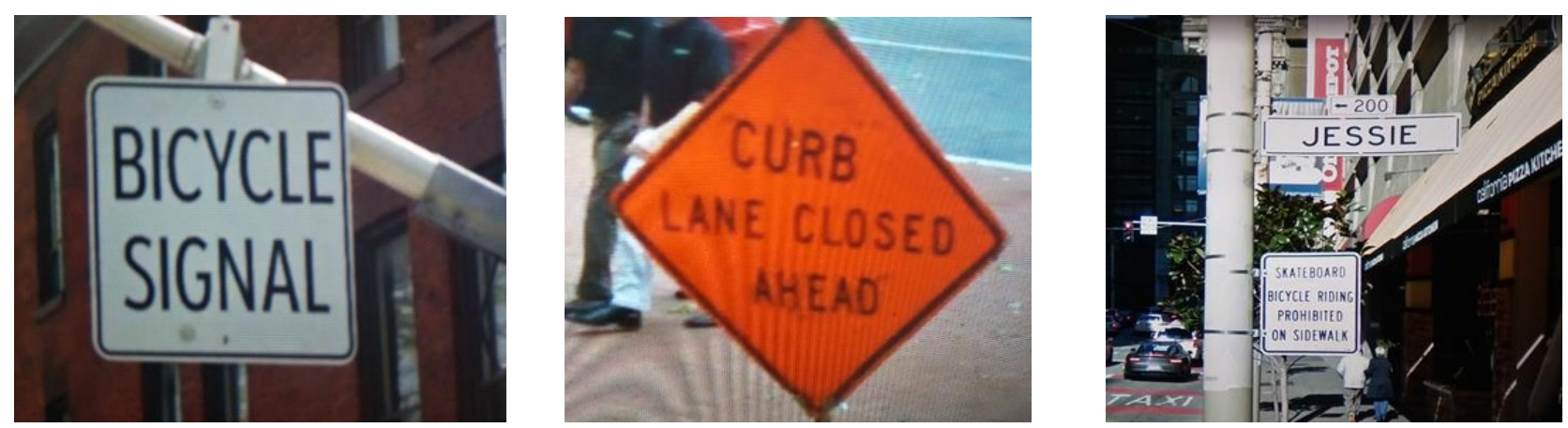

\section{Sayings and Proverbs}

The streets are also rich of sayings and proverbs. Some are displayed by business enterprises such as those by Good Foods Markets, and students can use the search engines to get more information about the sayings and proverbs, such as, "Grow up strongs and harmless," "Eat like an idealist," "There are a lot of fish in the sea, and some should stay there."

Linguistic-landscape-based activities will keep the students engaged in information finding on the internet to discover the meanings of those sayings and present them to the class. About "Grow up strong and harmless," for instance, students can discover that the piece of advice by Good Food Markets intended for young girls has sparked online controversy provoked by the word choice "harmless." From the controversy students can also learn about how critical the general public is towards word choice. This is a language learning exercise that facilitates the students to the practical experience of language as a social phenomenon.

The general public question why girls should be harmless, as they think that it is a sexist remark. They associate the word harmless to unassertiveness and dependence. In spite of the public protest, through their research students can continue to discover that the word "harmless" is used by Good Foods Market to describe that girls should raise their health awareness to grow strong and to be harmless to the earth. This advice is in accordance with the Good Foods Market's policy in promoting 
affordable green, organic high-quality produce for everyone-not to mention protecting the environment from harmful pesticides.
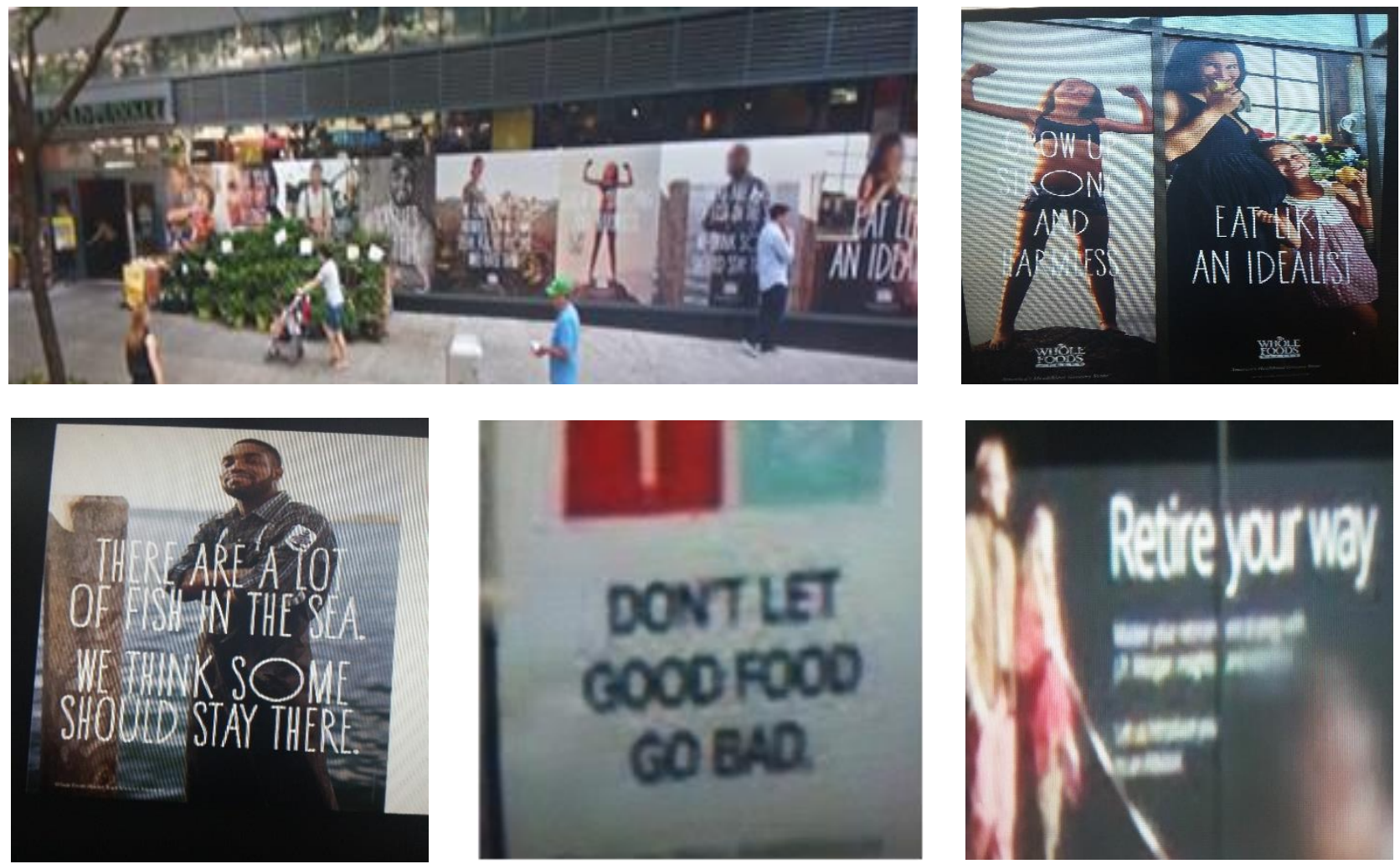

The government also issues posters with sayings and proverbs posted on public spaces, especially at bus stops. USDA (United States Department of Agriculture), for example, issues a poster with the theme "Don't let good food go bad." The purpose of the poster is to prevent public from food spoilage. Food waste is a serious concern in the USA, as it is equal to economic loss. Good nutrition and dietary behavior is important for the country, where 15 percent of people lack adequate nutrition. Using their search engines, students can easily find the extensive explanation about the saying both by the government and by the communities of interest. The saying has even turned to be a fabricated pattern-a form that learners need to learn to develop their phraseological skill or word-combining skill:

(1) Don't let good food go bad.

(2) Don't let good food spoil

(3) Don't let good veggies go bad

(4) Don't let good produce go bad

(5) Don't let good meat go bad

(6) Don't let good fruit go bad

(7) Don't let food poisoning spoil your holiday

(8) Don't let leftovers spoil your holiday

\section{Idioms}

Another type of lexico-grammatical unit is idiom. Linguistic landscape is a good means to help students learn new idioms, like spic and span and the dog's bollocks. Using Google Maps a learner can virtually travel down Dundas St. West in Toronto, Canada, and they will find a Laundromat called "King Spick and Span Laundromat, Inc." Spick itself means a nail or a spike. The word is associated with the Dutch expression spiksplinternieuw, a word to refer to a freshly-built ship with all-new nails and timber. Span is borrowed from Old Norse, and it means new. In English spick and span means spotlessly clean and well looked after like new. 

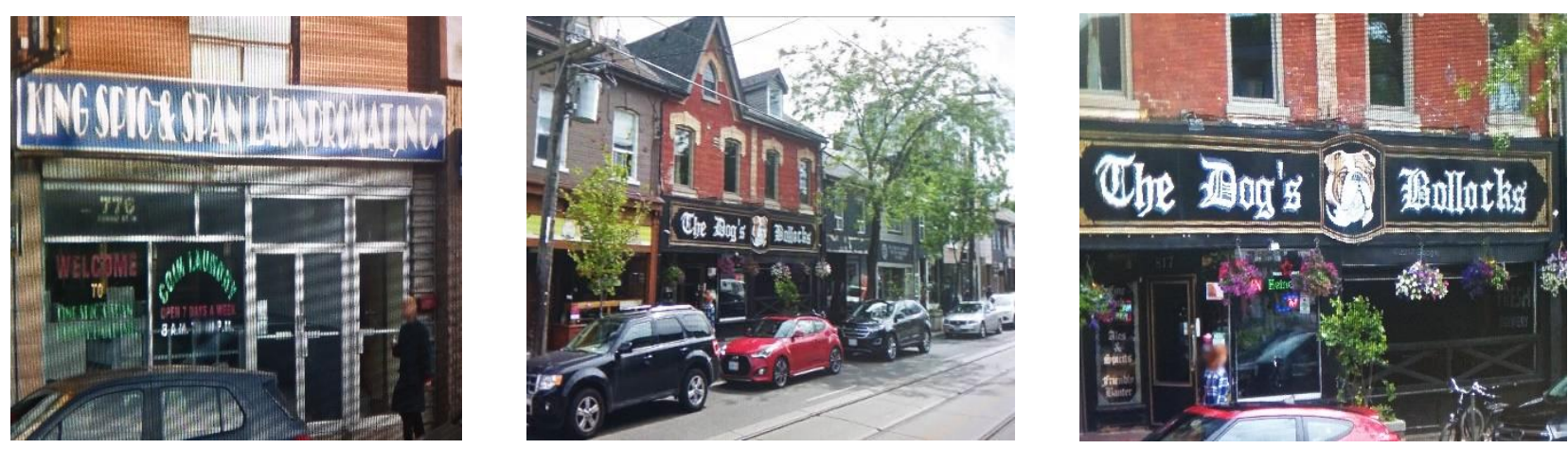

When the learner continues his virtual trip to Queen St. West, Toronto, they will find a restaurant called "The Dogs' Bollocks." Bollocks in old Anglo Saxon means testicles. The word bollocks also bears a negative connotation such as "that's bollocks" which means "that's rubbish"; and "to drop a bollock" which means the malfunction of an operation. However, dog's bollocks is a UK slang term meaning the very best. Therefore, if the restaurant is called "The Dog's Bollocks", it does not imply that restaurant is not a decent place to eat. The food served has nothing to do with dog meat or dog testicles. In fact, the restaurant is famous for its chicken wings, burger selection and outstanding butter chicken, to mention few.

\section{IMPROVING PRAGMATIC COMPETENCE}

Linguistic landscape does not only give learners of English the opportunity to develop their linguistic competence and their comprehension skill in understanding propositions, but also pragmatic competence. Language does not only convey bald facts asserted directly in utterances and sentences, but also communicates pragmatic implications, or contextual implications. Having the competence of pragmatic implication, a learner will develop their skill to understand the speaker's or the writer's intentions when they produce their utterances. Learners need to know that in numerous cases what a speaker means goes beyond what is literally said.

Pragmatic implications are defined as statements that lead a person to believe something that is neither explicitly stated nor necessarily implied. It is widely used in advertisement for achieving the marketing and persuasive goals; language is not only used as a tool for sending information, but also for convincingly persuading or even manipulating the readers. A lot of verbal texts on the street are advertisement. Being exposed to advertisement learners become more aware of language creativity, the power of words for influencing people, and the increasingly prominent role of language in business. Learners will also learn how skillful the advertisers are in using well selected words mainly to promote a product or service but the word choice should still comply to the advertisement regulations. Learning this, learners will be prompted to expand their vocabulary to make themselves proficient with the complexity and the sophisticated subtleties of word choice. This will also be a good exercise for advance learners to express themselves clearly by pretending themselves as marketers, and create their own mock advertisements or any other signs. They will learn how to captivate passersby or potential customers with efficient and effective language without violating the ethical standards commonly applied to business communication. Basically, advertisements have the role to seduce, attract, manipulate, persuade, lie and eventually inform (Crisan \& Pop, 2013), and their success depends on the advertisers' large vocabulary size, imagination, and the ability of using the right words. English language is known for its extensive vocabulary. One word may have six synonyms in English, and they may differ very slightly with different connotational meaning and in a very subtle way. Therefore, as stated by Hewitt-Bradshaw (2014) signs in public spaces increase the learners' critical language awareness and hold much potential to propel language and literacy development. It is a resource in teaching which recognizes the social context of language learning and use.

Language is used playfully in urban signage; especially in places most visited by young people. The language is adjusted to their pop culture trendy taste. This is another pragmatic dimension that a learner can learn on the street. Learners can see how texts are shaped by the contexts of use. They can collect the authentic English they can find in public spaces. Student can capture those written texts with their cameras and share them to their friends and memorize them. They can also learn a culture different from their own, and find so many signs that they do not have the equivalents in their own countries.

On Queen Street West Toronto, for example, a learner will find the shop sign "Locks \& Mane, hair extension bar." To make the shop name meaningful, a learner should first of all know that lock is a polysemous word, and he has to use his linguistic competence to interpret its meaning in context. Obviously, in this context lock is not a device for securing a door. Instead, it is associated to a lock of hair, while mane is to the mane of a horse or the mane of an adult male lion. Through this process of 
interpretation, the name Locks \& Mane is relevant to the description of the shop hair extension bar. Following this, he can easily guess that the shop is a hair salon specializing itself in hair extension services.
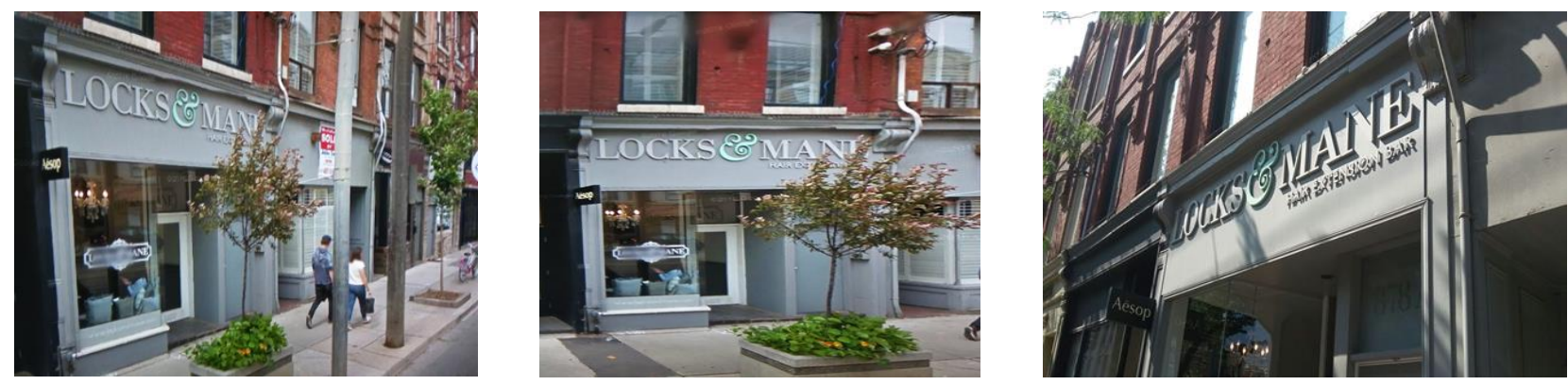

A native speaker who understands word play in English will readily find that the name Locks \& Mane is creative and interesting. In contrast, it is hard to imagine that the name will be used for a salon in Indonesia. It will only be catchy and meaningful for English native speakers. Both the words lock and mane are low frequency words, so hardly do the people living in a non-English speaking country like Indonesia understand the meaning of the shop sign. In general, they may guess that the establishment has something to do with hardware business. As a marketing tool, hair dressers in Indonesia also incline to name their salons in English to sound trendy and classy. However, the names they use are normally simple, familiar English words, like My Salon, Happy Salon, Cherry Salon, or Lady Salon.

If a learner is not easily satisfied with his linguistic competence, and he wants to develop his pragmatic competence, he will go deeper to discover a range of possible implications the owner wants to tell the prospective customers about his salon. The word lock keeps a number of implicit meanings. The first is that lock is a safe and painless method for hair extension, using human hair, and without chemicals, heat and glue, and it is good even for fragile hair. Secondly, hair does not decompose. Therefore, people cherished it as a symbol of eternal life. To the mid-20th century locks of hair was also a token of friendship or love. In the West, families often passed down keepsakes of locks of hair tied with string or colorful ribbon hair from generation to generation.

About mane, it is a symbol of maturity, health and potency. Thick, lush mane for a lion indicates serious power. Locks \& Mane wants to convince potential customers that how thin their natural hair is, the staff of the salon can successfully give them the look of fullness and power to their hair.

Locks \& Mane is an example of the use of English for a marketing goal. It is a source for learners to learn how choice of words and wordplay are not only informative, but also amusing, lively and entertaining. Advertisement is a good source for learners to raise their awareness of lexical choice. Advertisers know how to use word choice to boost persuasive powers in convincing potential customers without violating ethical standards commonly applied to business communication. Learning to use a word like an advertiser leads learners to consider different perspectives of language use such as economics, law, history, psychology (Rotfelt \& Stafford, 2007).

\section{IMPROVING INTERCULTURAL COMPETENCE}

UNESCO (2013) points out that intercultural competence becomes more important in a more diverse and shrinking world to promote mutual understanding, peace and democracy. Intercultural competence is an ability to become sensitive and respectful to cultural differences in situations when they perform their verbal communication in intercultural interactions. Intercultural sensitivity and solidarity help people to live together peacefully, free and equal. Intercultural skills develop through an ongoing learning process that involves curiosity and discovery. Therefore, a fundamental element in intercultural competence development is an opportunity to discover and evaluate as well as to analyze and interpret various phenomena that are related to other cultures (Walinski, 2013). Linguisticlandscape-based activities with Google Maps fit well to and stimulate the learners' process of curiosity, discovery, analysis and interpretation for the development of intercultural competence.

\section{About Java}

Equipped with Google Maps, students can discover that in downtown Toronto there are two restaurants called Java; one is called Java House on Queen Street West, and the other is Juice and Java Cafe \& Restaurant on Queen Street East.

It is interesting that the storefront sign of Java Cafe or Java House presents the picture of a stilt house. The drawing is sandwiched between the word Java and the word cafe, giving the impression that houses on the island of Java in Indonesia were wooden and on stilts. The sign maker may expect that the picture of the stilt house in green wilderness may quickly capture the customer's interest and draw 
them in, because the imagined raw environment and exoticness may give the customers the feeling of a break from the hectic urban Toronto, where they are in. In spite of the commercial goal, the picture does not really represent the Island of Java in Indonesia. Houses on Java Island in Indonesia are not on stilts. Traditional stilt houses were common in rural South Kalimantan, where houses were predominantly built on rivers. Indonesia has more than 1700 islands, and Java is the fourth largest island in the country, and the most developed in Indonesia. Jakarta, the capital of the country is also located on Java. About 145 million people live on the island, and it is one of the most populous islands in the world.

Understanding the situation above, through the linguistic-landscape-based activities with Google Maps, English language learners from Indonesia do not only learn about the target culture, but also discover how the outside world may perceive about their own culture; and they can also learn, be aware of and value their own unique culture even more. This awareness will help learners gain insights into different perspectives and make wise, informed decisions in understanding others and effectively communicating with others.
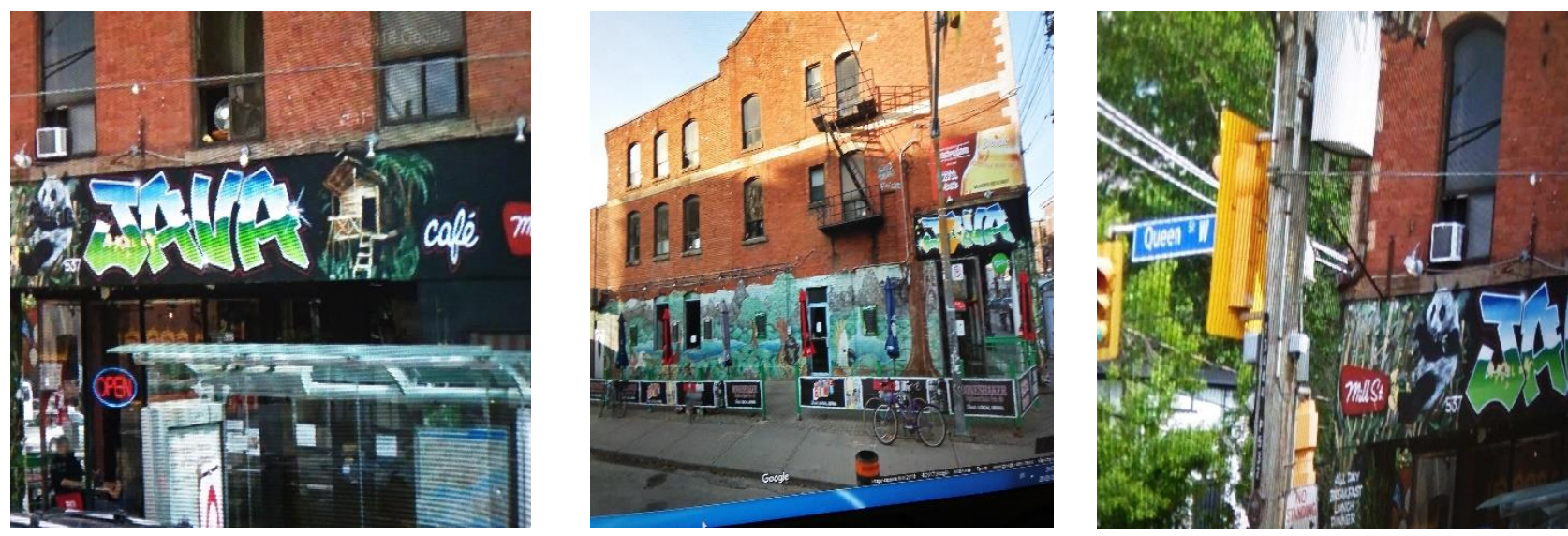

Triggered by the restaurant named Java in Toronto, to understand own culture, Indonesian learners may continue to explore and discover about their own history and culture. Dutch traders were likely the first to introduce the name Java to the world after the Island of Java. Today people in the West use the word for any coffee from Indonesia, no matter it is from the Island of Java or other islands. It has even become a generic term, and is not restricted any more for coffee from Indonesia. That Java is widely associated with coffee, a programming language called Java was released in 1995 with a steaming cup of coffee as its icon.
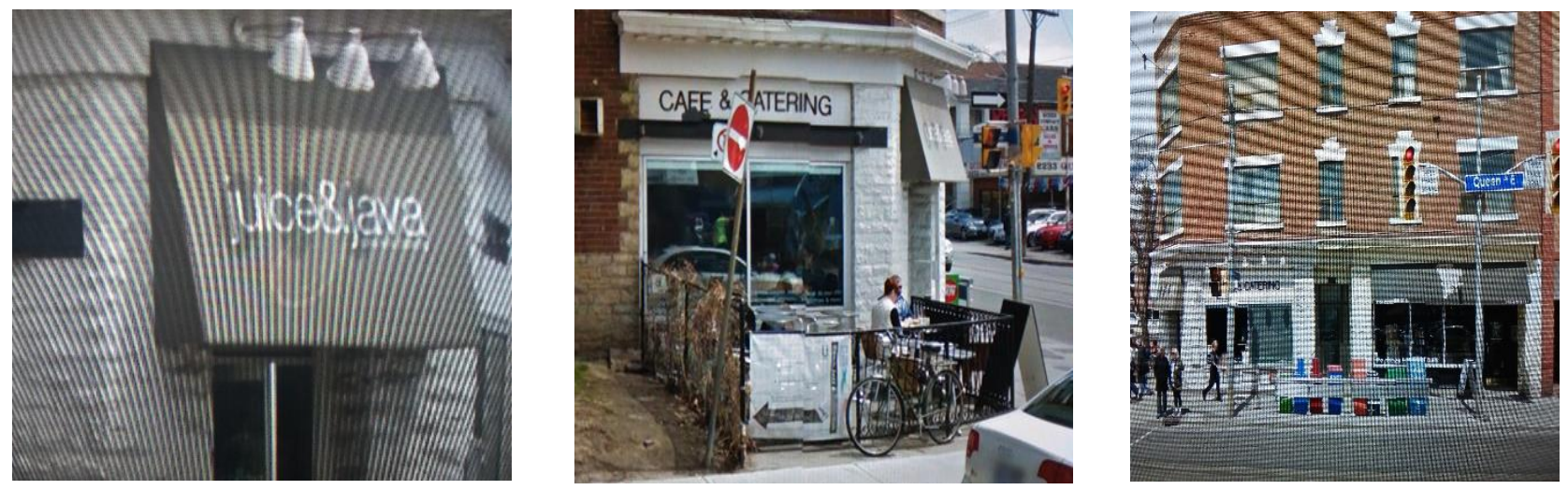

The cafe and restaurant is called Java mainly because it serves Java coffee-although it also serves beer and others. Arabica and Robusta coffee beans are planted and produced in Java, but Indonesians do not name their coffee Java coffee. In Indonesia coffee is called by its local or national brands such as Kopi Kapal Api, Tora Bika, ABC, but none is called Java.

In Toronto restaurants named Java do not serve Indonesian dishes. They serve both Western and Asian cuisines, but the Indonesian one is not included. Java Cafe serves Western food like ham \& cheese omelet, and Asian food like Vietnamese beef noodle soup, chicken pad Thai, Shanghai noodles. Juice and Java Cafe serves crepe, latte, soups, sandwiches, and omelet. In contrast, in Indonesia if restaurants are called Java, they will serve various dishes of Javanese Cuisine. Javanese cuisine is also influenced by Indian, Chinese, Arab, and European traditions. Those who have been travelling in Java will discover a sumptuous array of Javanese delights; meat is flavorful as it is marinated and cooked 
with aromatic culinary herbs and spices like turmeric, ginger, chili, onion, garlic, lemon leaves, lemon grass, galangal, coriander seeds and leaves.

About Church

A language learner, walking down Queen Street in Toronto, Canada, will find a sign read "CHURCH-Restaurant and Bar" at the corner of Queen West and Dovercourt. To understand the sign, he needs sufficient knowledge about the building. The sign "Church" displayed at the building front has more meaning than what is directly asserted there. It used to be a Slavic Pentecostal Church Building before it was sold to the restaurant owner. The church building exterior remains unchanged; it is still kept as historic, architectural treasure although the function has changed.
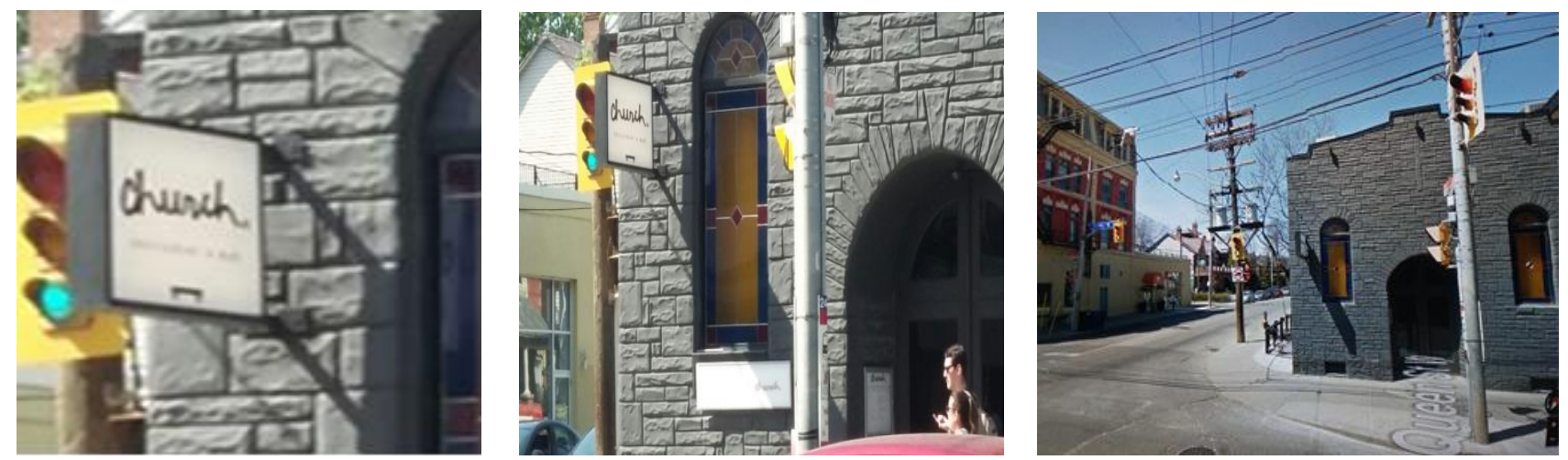

Some people resist the idea of a disused church building turning to a bar, and some others accept it. For some it is considered disrespectful to call a bar "church", while for the others it is considered as a way to keep the historic value of the building. A lot of research has been conducted and a lot of books have been written about the new uses of former church buildings. If learners are interested in this topic, they can explore the subject further.

Because of the dwindling congregation, increased secularization, shifting demographics, high maintenance costs, and limited finances to upgrade old buildings, many church buildings in Canada become homes, restaurants, bookstores, breweries, and other functions. About 500 churches have been closed in the last decade. Toronto used to be one of the most churched places in the world. However, most churches are empty today. In 2005 eighty-one percent of Canadians reported that they believed in God, but the percentage has declined to $65 \%$ in 2016. Nevertheless, Canada's official national anthem still includes a prayer "God keep our land glorious and free." The following is the first verse of the anthem:

\section{O Canada!}

Our home and native land!

True patriot love in all thy sons command.

With glowing hearts we see thee rise,

The True North strong and free!

From far and wide,

O Canada, we stand on guard for thee.

God keep our land glorious and free!

O Canada, we stand on guard for thee.

O Canada, we stand on guard for thee

A situation like disused church building does not take place in a country like Indonesia, where there is always a great demand for building new places of worship. Indonesia does not recognize agnosticism or atheism, and religious affiliation to one of the six officially recognized religions is part of social and legal identity. Places of worship are highly respected by the followers of the respective religions, and it is very unlikely for a restaurant to be named Church in Indonesian context.

\section{CONCLUSIONS AND SUGGESTIONS}

Today information technology has successfully helped English language learners in non-English speaking countries in creating English language learning environment. This paper shows how Google Maps can help learners to develop their linguistic, pragmatic and cultural competence through 
linguistic-landscape-based learning activities. The activities keep students engaged in curiosity, discovery, and internet search.

Linguistic landscape activities help learners to deliberately develop their linguistic skill through interesting virtual trip to English speaking countries. The activities can turn the classroom to be a learning environment rich of lexico-grammatical units, including sayings, idioms and prefabricated patters which can meaningfully develop learners' vocabulary skills. Knowledge of lexico-grammatical units is important for learners when they want to approximate themselves to native speakers' competence.

Urban commercial areas are also rich of outdoor advertisements, and it will be a good resource for learners to develop their skill in pragmatic implications. Learners can collect authentic, playful English in the advertisements they encounter on the streets, bring them to the class and have in-class discussion about how language creativity can lead people to believe in something like an advertised product.

Google Maps is also potential to keep students engaged in linguistic landscape activities to discover cultural differences and to develop their intercultural competence. They do not only learn about target culture, but they will also learn how the outside world perceives about their own culture. This understanding will help them value their own culture, and make wise, informed decisions to understand people of others cultures and to effectively and appropriately communicate, empathize and work with them.

\section{REFERENCES}

Bell, N., 2012. Formulaic Language, Creativity, and Language Play in a Second Language, Annual Review of Applied Linguistics, 32, pp. 189-205.

Chern, C. \& Dooley, K. 2014. Learning English by walking down the street. ELT Journal, Advance Access, published January 15, 2014.

Crișan, R. \& Pop, A. 2013. The Efficiency of. Pragmatic Implicature in the Language of Tourism. The. International Scientific Conference Literature, Discourse, and Multicultural Dialogue, 1st Edition. Targu Mures, Petru Maior University, ISI Proceedings, pp.156-61.

Duraiswamy, M. (2014). Chunks-based Language Learning-Theory and Practice For the Classroom. Ideas from the Corpora, 16(2).

Hewitt-Bradshaw, 2014. Linguistic landscape as a Language Learning and literacy resource in Caribbean creole contexts. Caribbean Curriculum, 22, 157-73.

Kweldju, S. 2001. Presenting Grammar in the Teaching of Grammaticalised Lexis: the Balance of Grammar and Vocabulary for Improving Reading Skill. Jurnal Teknologi Pembelajaran, 9(1).

Lewis, M. 1997. Implementing the Lexical Approach. Hove: Language Teaching Publications.

Nattinger, J. R. And J. S. DeCarrico. 1992. Lexical Phrases and Language Teaching. Oxford: Oxford University Press.

Rotfelt, H.J. \& Stafford, M.R. (2007). Toward a Pragmatic Understanding of the Advertising and Public Policy Literature. Journal of Current Issues and Research in Advertising, 29(1), pp. 67-80.

UNESCO, 2013. Intercultural competence: Conceptual and Operational Framework. http://unesdoc.unesco.org/images/0021/ 002197/219768e.pdf

Walinski, J.T. 2013. Relevance of Linguistic Landscape to Intercultural Competence Development in the context of Situated Learning. International Journal of Mobile and Blended Learning, 6(2), pp.114.

Wray, A. 2000. Formulaic Sequences in Second Language Teaching: Principle and Practice. Applied Linguistics, 21(4), pp.463-89. 